\title{
Abdominoscrotal hydrocele in an infant boy
}

\author{
Eliana Costantino, George S Ganesan, J Chadwick Plaire
}

Children's Urology Associates, Las Vegas, Nevada, USA

\section{Correspondence to} Eliana Costantino, elianacb@gmail.com

Accepted 11 May 2017
To cite: Costantino $E_{\text {, }}$ Ganesan GS, Plaire JC. BMJ Case Rep Published Online First: [please include Day Month Year]. doi:10.1136/ bcr-2017-220370

\section{SUMMARY}

Abdominoscrotal hydrocele (ASH) is the rarest type of hydrocele. This condition is characterised by a large abdominal and scrotal component connected by an isthmus within the inguinal canal. The incidence among the paediatric population is reported to be less than $3 \%$, although it might be underdiagnosed. Several theories have been proposed in the literature but the aetiology of ASH remains unknown. Diagnosis can be made clinically and confirmed by ultrasound. Spontaneous resolution is rare and long-standing ASH may lead to complications, thus early surgical intervention is recommended. Different techniques have been described, but dissection remains challenging due to the tunica vaginalis adherence to the testis and the distal cord. We present a male infant with ASH who underwent inguinal repair. The procedure was facilitated by needle decompression of the mass. Identification and preservation of the vessels and vas deferens was done successfully without compromising the testis.

\section{BACKGROUND}

Abdominoscrotal hydrocele (ASH) is an unusual variety of the common scrotal hydrocele, characterised by a large abdominal component and a scrotal component connected by an isthmus within the inguinal canal. ${ }^{12}$ It is the rarest type of hydrocele, with a reported incidence between $0.4 \%$ and $3.1 \%$ of the paediatric hydroceles, although this condition might be under diagnosed. ${ }^{3-5}$

Patients are usually asymptomatic, but longstanding ASH may lead to complications that are mainly pressure related. These include hydronephrosis, hydroureter, testicular dysmorphism, testicular torsion, effect on spermatogenesis, spontaneous rupture or haemorrhage, and malignant transformation such as mesothelioma due to neoplastic change in peritoneal lining. ${ }^{26-8}$ Because spontaneous resolution in ASH cases is rare, early surgical intervention is recommended. ${ }^{34}$

\section{CASE PRESENTATION}

We present a 6-month-old male infant with a large right cystic inguinoscrotal mass that had been increasing in size since birth. The remainder of the examination was normal. Suspecting ASH clinically, imaging studies were obtained to confirm the diagnosis.

\section{INVESTIGATIONS}

Abdominal ultrasound showed unremarkable appearance of the intra-abdominal organs. Scrotal ultrasound described bilateral hydroceles. On the right side, a large $\mathrm{ASH}$, which extended through the inguinal canal into the pelvis adjacent and superior to the bladder, was reported. The maximal cross section was approximately $4 \mathrm{~cm} \times 3 \mathrm{~cm}$, and the intrapelvic portion measured approximately $4 \mathrm{~cm}$ (anteroposterior) $\times 6 \mathrm{~cm}$ (longitudinal) in the sagittal projection. On the left side, a moderate sized hydrocele that extended into the inferior inguinal canal but did not appear to extend into the abdomen was identified. There was no evidence of bowel herniating through the inguinal canals on either side, and both testicles had unremarkable appearance.

\section{DIFFERENTIAL DIAGNOSIS}

Differential diagnoses include spermatic cord lymphangioma, giant hydronephrosis, bladder diverticulum and pelvic neuroblastoma. ${ }^{6}$

\section{TREATMENT}

At 9 months of age, the patient underwent surgical repair through an inguinal approach. A dilated cystic dumbbell-shaped mass, which extended from the scrotum to the abdominal cavity above the internal ring, was identified. Needle decompression with a 14-gauge Angiocath was performed to facilitate the dissection, and $200 \mathrm{~mL}$ of fluid was evacuated before the mass collapsed completely (figure 1). Once the vessels and vas deferens were identified and carefully separated from the thick wall of the sac, the preperitoneal component was excised. The scrotal component, including the testis, was delivered to the operating field and the tunica vaginalis was excised without attempting complete removal in order to avoid injuring the testis.

\section{OUTCOME AND FOLLOW-UP}

Mild swelling was present as expected during the postoperative period, and resolved with time.

\section{DISCUSSION}

In 1834, Dupuytren was the first one to describe this condition as 'hydrocele en bisac,' later defined as ASH by Bickle in $1919 .{ }^{8-10}$

There are different types of hydrocele (figure 2). Adult or vaginal hydrocele is the most frequent type, where the processus vaginalis is obliterated but some scrotal fluid is present between the layers of the tunica vaginalis enclosing the testis (figure 2A). Infantile hydrocele is seen when the distal portion of the processus vaginalis, within the inguinal canal, fails to become obliterated so that the cavity of the tunica vaginalis extends partly into it (figure 2B). Communicating hydrocele is characterised by a 


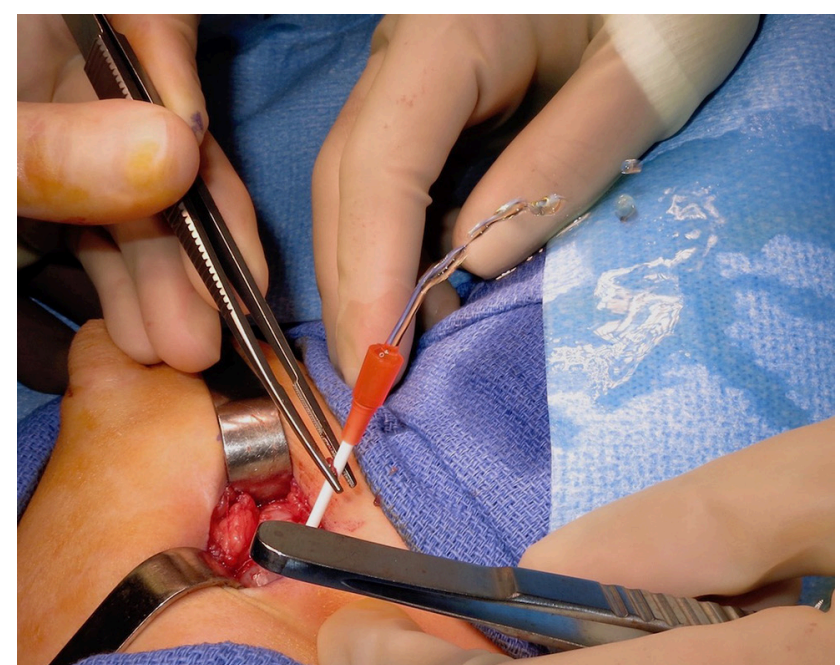

Figure 1 Intraoperative fluid decompression of the mass.

patent processus vaginalis (PPV) that provides a communication between the peritoneal cavity and the scrotal hydrocele (figure 2C). Hydrocele of the cord is seen less commonly, and occurs when an abnormal closure of the processus vaginalis results in fluid accumulation alongside the spermatic cord (figure $2 \mathrm{D}$ ). $\mathrm{ASH}$ is the least common variety, described as a cystic abdominal mass in association with a scrotal hydrocele (figure 2E).

The lack of a separate code for this condition may justify the difficulty in estimating its incidence when searched electronically. ${ }^{4}$ Cyst and hydrocele of the canal of Nuck have been reported in women. ${ }^{11}$ Few reports have been noted in adults, likely due to the progression of an ASH undiagnosed during childhood. ${ }^{7}$ There have been also reports of diagnosis in utero. ${ }^{4}$
The aetiology of ASH is unknown, but different theories have been suggested. The most accepted is derived of Dupuytren's theory (cephalad extension) on the basis of Laplace's law, which Brodman proposed could be due to a high partial obliteration of processus vaginalis near the internal inguinal ring. Inexpansible musculofascial walls bind the inguinal canal. When the increasing intracystic pressure within the scrotal component, which is transmitted to the internal ring, exceeds the intraperitoneal pressure, the tunica vaginalis protrudes into a place of less resistance. Thus, the abdominal component of the hydrocele develops and extends superiorly into the extraperitoneal space, retroperitoneal or preperitoneal. Other theories include an increased production or a decreased resorption of fluid; a peritoneal diverticulum herniation into the inguinoscrotal space (caudad extension); or a one-way valve-like mechanism within a PPV at the internal inguinal ring, although most authors deem the ASH to be a non-communicating hydrocele citing the intraoperative absence of PPV as evidence. 36791213

ASH should be suspected if a scrotal swelling is present in combination with abdominal swelling just above the inguinal ligament. Generally, it presents unilaterally with an equal distribution, but rarely can be found to be bilateral. ${ }^{6}{ }^{14}$ The abdominal component is usually larger than the scrotal counterpart. ${ }^{13}$ The widened internal ring may be associated with an inguinal hernia. $^{15}$

Diagnosis of ASH can be made by clinical examination alone, with demonstration of a hydrocele and an abdominal mass that are cross fluctuant. ${ }^{1-3}$ The 'Springing Back Ball' sign is a useful manoeuvre in which by compressing the scrotal swelling, the fluid is balloted into the abdominal component but then it springs back into the scrotum, usually spontaneously or by applying pressure over the suprapubic area or lower abdomen. ${ }^{5}$ Additionally,

\section{A. Adult (Vaginal) Hydrocele}

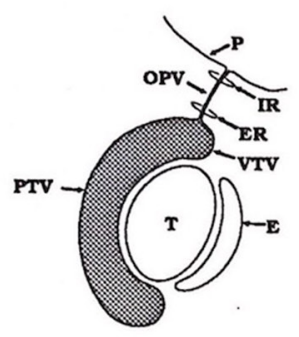

B. Infantile Hydrocele

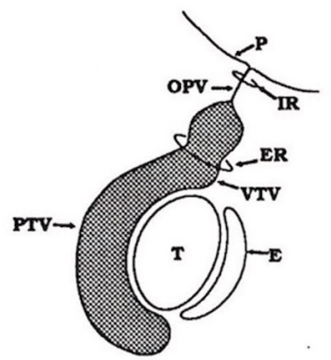

\section{Communicating Hydrocele}

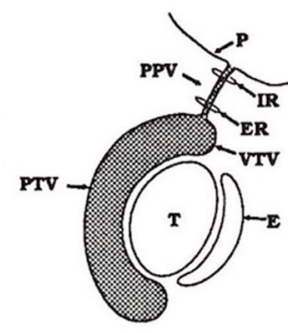

\section{Hydrocele of the Cord}

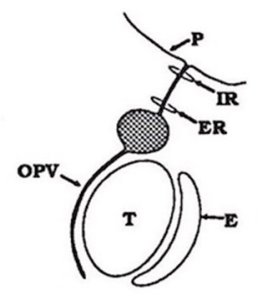

\section{E. Abdominoscrotal Hydrocele}

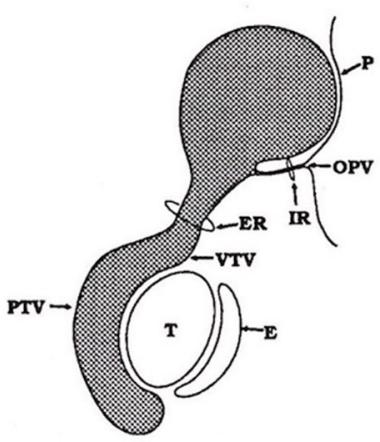

Figure 2 (A-E) Classification of the various types of hydrocele. E, epididymis; ER, external inguinal ring; IR, internal inguinal ring; OPV, obliterated processus vaginalis; P, peritoneum; PPV, patent processus vaginalis; PTV, parietal tunica vaginalis; T, testis; VTV, visceral tunica vaginalis. 


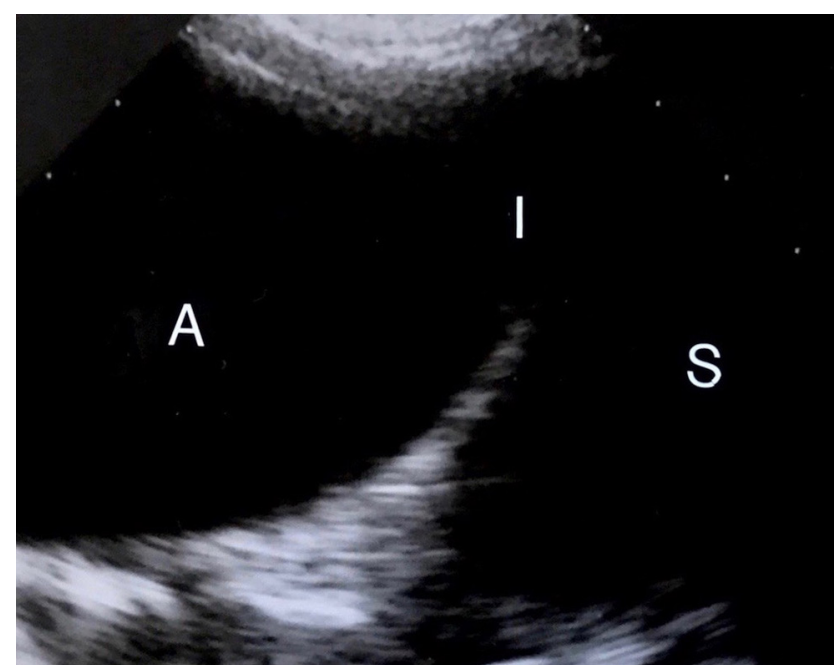

Figure 3 Ultrasound showing abdominal (A) and scrotal (S) components of the abdominoscrotal hydrocele communicating through the isthmus (I).

an 'hour-glass transillumination' of both components may be evident upon transillumination of the sac in a darkened room. ${ }^{16}$

Ultrasonography can be used to verify the diagnosis. ${ }^{12}$ Dynamic examination by compressing the hydrocele while observing with the ultrasound probe is recommended. ${ }^{5}$ The findings of a cystic scrotal mass communicating through the inguinal canal with a similar abdominal mass in which bowel loops are absent would confirm ASH (figure 3). If caliectasis is observed on ultrasound, a diuretic renal scan should be included in the work-up.

In few selected cases, contrast enhanced CT or magnetic resonance imaging might be helpful to better describe the relation or effect on surrounding structures, although this is rarely necessary. ${ }^{3}$

Management is controversial. The approaches used to gain access to the ASH vary from surgeon to surgeon and from centre to centre. Combined inguinal and extraperitoneal approach, combined inguinal and intraperitoneal approach, combined inguinal and laparoscopic approach, and inguinal and/or scrotal approach have all been described in the literature. ${ }^{3} 817$ The surgery is often difficult because of adherence of the hydrocele to the cord structures, regardless of the technique used. ${ }^{8} 18$

\section{Learning points}

- Abdominoscrotal hydrocele is the least common type of hydrocele. In spite of multiple theories, further studies are necessary to determine the exact aetiology.

- This condition might be underdiagnosed, and if so its incidence is probably higher than reported in the literature.

- Early surgical intervention is recommended as spontaneous resolution is rare and long-standing abdominoscrotal hydrocele may lead to complications.

- Needle decompression of the mass during the repair facilitates the dissection, which is particularly challenging due to the thickened tunica vaginalis adherence to the testis and the distal cord.

- An inguinal approach provides excellent exposure and access for both the abdominal and scrotal components, and allows excision of the majority of the wall sac without injuring the nearby structures.
Dissection of the distended and thickened tunica vaginalis is often facilitated by aspiration of the hydrocele fluid. ${ }^{1-378}$

In our experience, an inguinal approach provides excellent exposure and access for both the abdominal and scrotal components through a small incision in the inguinal skin crease line, which is cosmetically acceptable. Additionally, intraoperative fluid decompression enables the excision of the majority of the wall sac, while allowing identification and preservation of the vessels and vas deferens without compromising the testis.

Optimal time for surgery is unknown, but it has been described as early as 8 weeks, and surgical complications are usually minor, most commonly being inguinal/scrotal swelling. ${ }^{317}$ Regardless of the surgical approach, recurrences are not reported in the literature. Non-operative management with observation as the first step in uncomplicated asymptomatic and high surgical risk cases of ASH have also been reported in the literature, although as a less popular alternative to surgical excision due to complications if left untreated. ${ }^{5} 819$

Contributors All persons who meet authorship criteria are listed as authors, and all authors certify that they have participated sufficiently in the work to take responsibility for the content as guarantors. All authors participated equally in the concept and design. EC contributed to the literature review and manuscript preparation. GSG and JCP helped with implementation and revision. All authors contributed to the reporting and approved the final manuscript.

Competing interests None declared.

Patient consent Consent obtained from guardian.

Provenance and peer review Not commissioned; externally peer reviewed. (c) BMJ Publishing Group Ltd (unless otherwise stated in the text of the article) 2017. All rights reserved. No commercial use is permitted unless otherwise expressly granted.

\section{REFERENCES}

1 Ferro F, Spagnoli A, Lucchetti MC, et al. Abdominoscrotal hydrocele: a reliable surgical technique. Urology 2000;55:771-3.

2 Spataru RI, Iozsa DA, Nisipasu Cl. Abdominoscrotal hydrocele, an underestimated entity. Jurnalul pediatrului 2014;XVII:65-6.

3 Doudt $A D$, Kehoe JE, Ignacio RC, et al. Abdominoscrotal hydrocele: A systematic review. J Pediatr Surg 2016;51:1561-4.

4 Cozzi DA, Mele E, Ceccanti S, et al. Infantile Abdominoscrotal Hydrocele: A Not So Benign Condition. J Uro/ 2008;180:2611-5.

5 Khorasani M, Jamieson DH, Langer $\mathrm{K}$, et al. The treatment of abdominoscrotal hydrocele: Is there a role for nonoperative management? J Pediatr Surg 2016;51:815-8

6 Kamble PM, Deshpande AA, Thapar VB, et al. Large abdominoscrotal hydrocele: Uncommon surgical entity. Int J Surg Case Rep 2015;15:140-2.

7 Cuervo JL, Ibarra H, Molina M. Abdominoscrotal hydrocele: its particular characteristics. J Pediatr Surg 2009;44:1766-70.

8 Blevrakis E, Anyfantakis DI, Sakellaris G. Abdominoscrotal hydrocele in a 9-month old infant. Hernia 2011;15:201-3.

9 Dupuytren G. In: Lecons Orales de Clinique Chirurgicale. Vol. 4. 444. Paris: G. Balliere, 1834.

10 Bickle LW. Abdominal or bilocular hydrocele. Br Med J 1919;2:13.

11 McCune WS. Hydrocele of the Canal of Nuck with Large Cystic Retroperitoneal Extension. Ann Surg 1948;127:750-3.

12 Brodman HR, Brodman LE, Brodman RF. Etiology of abdominoscrotal hydrocele. Urology 1977;10:564-5.

13 Virgilio E, Mercantini P, Tallerini A, et al. Abdominoscrotal hydrocele: when one sac becomes bissac. ANZ J Surg 2015.

14 Prather GC. Abdominoscrotal hydrocele. Review of the literature and report of a case. N Engl J Med 1942;226:255

15 Martin K, Emil S, Laberge JM. The value of laparoscopy in the management of abdominoscrotal hydroceles. J Laparoendosc Adv Surg Tech A 2012;22:419-21.

16 Keihani S, Hojjat A, Kajbafzadeh AM. Abdominoscrotal Hydrocele: Role of Physical Exam and Transillumination in Diagnosis. J Pediatr 2015;167:1448.e1.

17 Kajbafzadeh AM, Talab SS, Elmi A, et al. Modified scrotal approach for correction of abdominoscrotal hydrocele in children: clinical presentation and description of technique. Urology 2010;76:87-91.

18 Hisamatsu E, Takagi S, Nomi M, et al. A case of bilateral abdominoscrotal hydroceles without communication with the peritoneum. Indian J Urol 2010;26:129-30.

19 Czerwińska K, Brzewski M, Majkowska Z, et al. The abdominoscrotal hydrocele in the infant - case report. Pol J Radio/ 2014:79:108-11. 
Copyright 2017 BMJ Publishing Group. All rights reserved. For permission to reuse any of this content visit http://group.bmj.com/group/rights-licensing/permissions.

BMJ Case Report Fellows may re-use this article for personal use and teaching without any further permission.

Become a Fellow of BMJ Case Reports today and you can:

- Submit as many cases as you like

- Enjoy fast sympathetic peer review and rapid publication of accepted articles

- Access all the published articles

- Re-use any of the published material for personal use and teaching without further permission

For information on Institutional Fellowships contact consortiasales@bmjgroup.com

Visit casereports.bmj.com for more articles like this and to become a Fellow 